\title{
A NOVEL TASTING PLATFORM FOR SENSORY ANALYSIS OF SPECIALTY COFFEE
}

\author{
Nelson Gutiérrez-Guzmán¹, Albeiro Cortés-Cabezas², Edgar Chambers IV ${ }^{3}$
}

(Received: July 13, 2018; accepted: August 07, 2018)

\begin{abstract}
Although there are many good tools to evaluate coffee, such as rigorous cupping protocols, all of them require improvements in order to benefit scientific research. One aspect to highlight is that coffee is a very important product worldwide and has been and is being investigated for its complexity. All research and any improvement in crop or processing ends-up being verified in the coffee cup quality, which is accomplished through the cupping procedures. However, sufficient tools have not been designed in order to manage the cupping procedures, in accordance with the technological level we have available now. Basically, sheets of paper are used to manage the cupping scores, which hinder the subsequent analysis process, making hard to know what happens inside coffee beans with greater precision and thoroughness. Another worrying aspect is that each region, at each country uses a different format with different flavor references to carry out the scoring, which has generated problems of unity of criteria on the analysis and this is not good to the coffee business. This paper presents the design of a web platform to make information storage and results processing of cupping procedures of specialty coffees easier. The main objective is to achieve better managing of the cupping model for the sensory analysis using a digital environment, allowing greater agility in the treatment of results and a more organized management of the information of the specialty coffees.
\end{abstract}

Index terms: Sensory evaluation of specialty coffee, cupping protocols, quality attribute, information systems.

\section{UM NOVO SISTEMA DE INFORMAÇÃO PARA A ANÁLISE SENSORIAL DE CAFÉS ESPECIAIS}

RESUMO: Embora existam diversas boas ferramentas para avaliar a qualidade do café, tais como os rigorosos protocolos de degustação, todas elas exigem melhorias para beneficiar a pesquisa científica. Destaca-se que o café é um produto de grande importância no mundo inteiro e tem sido investigado por sua complexidade. Toda pesquisa e qualquer melhoria na cultura e no processamento se verifica na qualidade da xícara do café por meio dos procedimentos de degustação. Porém, não foram desenvolvidas ferramentas suficientes para a gestão desses procedimentos de acordo com o nível tecnológico disponível atualmente. Basicamente, são utilizadas folhas de papel para armazenar os resultados da degustação, o que dificulta a análise subsequente e torna mais difícil saber o que acontece no interior do grão de café com maior precisão e rigor. Outro aspecto importante é que cada região em cada país utiliza um formato distinto com referências de sabor diferentes para atribuir a pontuação, o qual tem gerado problemas de unidade de critérios na análise, e isso não é bom para o negócio do café. Apresentase neste trabalho o desenho de uma plataforma web para facilitar o armazenamento e tratamento da informação dos resultados das análises sensoriais de cafés especiais. O objetivo principal é conseguir uma melhor administração do modelo de testes para a análise sensorial das amostras em um ambiente digital que permite maior agilidade no tratamento dos resultados e um manejo mais organizado da informação do café especial.

Termos para indexação: Análise sensorial de café especial, protocolos de degustação, atributos de qualidade, sistemas de informação.

\section{INTRODUCTION}

Coffee is one of the most popular and consumed drinks in the world, thanks to its organoleptic characteristics and stimulating effects (ALVES; CASAL; OLIVEIRA, 2010; DI BELLA et al., 2014). Due to this, since the 90s, the term "specialty coffee" has been used to refer to the quality of coffee, in order to describe one with excellent and unique flavor (PICCINO et al., 2014). During the last decade, there has been an increase in the knowledge of parameters that define the quality of coffee bean, among them stands out the value of the aromas and differentiating notes in the cup.

Currently coffee is grown in more than 70 countries, with Brazil being the largest producer, followed by Vietnam and Colombia (BICHO et al., 2013; DI BELLA et al., 2014). The Huila region is a pioneer in coffee production in Colombia, with 126 thousand hectares, where 2.5 million bags of 60 kilos were produced during 2016 and also leads the production of specialty coffees in the country.

The Strategic Plan for Science, Technology and Innovation 2010-2032 for the Huila region

${ }^{1}$ Centro Surcolombiano de Investigación en Café CESURCAFE/Universidad Surcolombiana -Departamento de Ingeniería Agrícola Cx.P. 410001 -Neiva - Colombia - ngutierrezg@usco.edu.co

${ }^{2}$ Departamento de Ingeniería Electrónica - Centro Surcolombiano de Investigación en Café CESURCAFE/Universidad Surcolombiana - Cx.P. 410001 - Neiva - Colombia - albecor@usco.edu.co

${ }^{3}$ Sensory Analysis Center/Kansas State University - Cx.P. 66506 - Manhattan - Kansas - USA - eciv@ksu.edu

Coffee Science, Lavras, v. 13, n. 3, p. 401 - 409, jul./sep. 2018 
identifies potentially strategic products to improve the economy of the region. It is clear, according to this plan, that the coffee sector occupies the most important place in the economy of Huila, after the oil sector. At this time, Huila is not only recognized worldwide for the large volume of coffee produced annually, but also for the excellent quality of it. Specialty coffees have been an economically important alternative to improve the income of producers and associative groups in the Huila region. However, specialty coffees involve a series of components and production systems designed to produce high quality coffee for international markets, which creates new forms of consumption focused on quality, differentiation and characteristics of coffee (SEPÚLVEDA et al., 2016).

The Specialty Coffee Association - SCA (SCAA, 2018) has established a very rigorous evaluation procedure, known as "cupping protocols" to determine the sensory profile of coffee beans, in order to grant the distinction of special coffees to coffees from different origins on the planet. Currently, the standard for cupping coffee is the most widely used method for sensory coffee evaluation. This procedure is extremely useful for coffee producers, buyers and other actors in the coffee value chain, in order to evaluate coffee quality and defects. The procedure takes into account several quality attributes simultaneously, including aroma/fragrance, flavor, residual flavor, acidity, body, uniformity, balance, clean cup and sweetness. Each attribute receives an assessment on a quantitative scale and the final score corresponds to the sum of the attributes evaluated. Only those coffees beans who get total scores higher than 80 points are considered "specialty coffees". The procedure also allows to include within the evaluation some notes to provide additional information about specific characteristics of each coffee (DI DONFRANCESCO; GUTIERREZ; CHAMBERS, 2014) (OYOLA; TRUJILLO; GUTIERREZ, 2017).

This cupping coffee test is carried out through panels of tasters who have been adequately trained to fully identify, define and understand the sensory characteristics that determine the quality of the coffee. A sensory panel is equivalent to any scientific instrument for measuring the characteristics associated with the quality of a food product (FERIA, 2002) (OYOLA; TRUJILLO; GUTIERREZ , 2017).
The instrument used by panel members of tasters to record the results of the cupping test is the Specialty Coffee Association of Coffee Cupping Form (SCAA, 2018). In some regions and countries this format is partially modified to adapt it to different work styles. According to our experience, all sensory panels agree on using paper formats to record this information manually, which makes the work more tedious and prone to errors. The above because to date a digital tool has not been developed to facilitate this work, as well as the statistical treatment of the information collected.

The objective in this work was to design an information system for the laboratory of the Southcolombian Coffee Research Center CESURCAFÉ of Surcolombiana University in Colombia to facilitate the storage and processing of information about the results of the cupping protocols carried out daily in this laboratory. The work is aimed at structuring the test model for the sensory analysis of samples in a digital environment, which allows agility in the treatment of results and more organized management of information. The system takes into account and includes the new sensory lexicon created by World Coffee Research - WCR, the largest collaborative work on coffee flavor that has been developed (CHAMBERS et.al, 2016) and also has language support in Spanish and English.

\section{MATERIALS AND METHODS}

\section{SCAA Metodology}

The set of protocols of the SCAA along with the new sensory lexicon from the WCR were the main input for the development of this work. The SCAA Technical Standards Committee recommends following these protocols in order to guarantee the ability to evaluate coffee with the highest quality through coffee cupping tests.

It must be taken into account that the coffee cupping tests are carried out on coffee samples and for three specific purposes:

To determine real sensory differences between coffee samples.

To describe the taste of the samples.

To determine preference for different types of coffee.

The scoring format used in the coffee cupping test allows registering 11 important attributes of coffee flavor: fragrance/aroma, flavor, residual taste, acidity, body, balance, uniformity, clean 
cup, sweetness, defects and global note. It cans be downloaded from the following URL: http://www. falconcoffees.com/wp-content/uploads/2016/06/ SCAA-score-sheet.pdf. These attributes receive positive scores according to the quality they reflect according to the judgment of value of the sensory panel. Defects receive negative scores and denote unpleasant taste sensations. The overall score is based on the taste experience of each individual taster as a personal valuation. These attributes are qualified using a scale including 16 values, which represent quality levels with steps of 0.25 points between each one, and starting at 6 and ending at 9.75. These levels are presented in Table 1 .

\section{Total score}

The total score is calculated by first adding the individual scores given to each primary quality in the box marked "total score". Then, defects are subtracted from total score. The total score is recorded in a box destined for it. The scoring guide, shown in Table 2 has proven to be a useful way to describe the quality ranks within the final score.

\section{The new sensory lexicon for brewed coffee}

The formulation of the WCR Sensory Lexicon as a universal language of sensory qualities of coffee and a tool to measure them is a first step to understand what makes coffee taste, smell and feel as it happens. This lexicon is aimed to achieve better research results and a better coffee. To overcome this challenge, it is also necessary to get good tools, which allow having a reliable and repeatable way to measure the flavors and their relative magnitude. The new lexicon allows to identifying a series of flavors that can be found in coffee and that are related to the production process from planting to cup. The 110 attributes contained in the new coffee lexicon are included in this tasting platform.

\section{Application model}

Figure 1 presents the general model of the platform. This platform is based on a multi-layer design, including a data, business and presentation layers. Data layer uses MySQL as database engine (MYSQL, 2018) and Hibernate, a relational object mapping tool for the Java programming language, which provides a framework for mapping an object-oriented domain model to a relational database. Some components of Spring Framework (SPRING FRAMEWORK, 2018) are used in the business layer. Spring is a framework for the development of high level enterprise applications and an open source for the Java platform. In the presentation layer, the Model-View-Controller MVC was adopted using Spring-webmvc, Html5, CSS3, JS and Bootstrap.

\section{Database}

MySQL was chosen as database engine. It is an open source system for relational database management, based on structured query language - SQL. This database manager is multi-threaded and multiuser, which allows it to be used by several people at the same time, and even, make several queries at once. This makes it extremely versatile.

TABLE 1 - Quality levels for coffee cupping test.

\begin{tabular}{cccc}
\hline Good & Very Good & Excellent & Outstanding \\
\hline 6.00 & $\mathbf{7 . 0 0}$ & $\mathbf{8 . 0 0}$ & $\mathbf{9 . 0 0}$ \\
6.25 & $\mathbf{7 . 2 5}$ & $\mathbf{8 . 2 5}$ & $\mathbf{9 . 2 5}$ \\
6.50 & $\mathbf{7 . 5 0}$ & $\mathbf{8 . 5 0}$ & $\mathbf{9 . 5 0}$ \\
6.75 & $\mathbf{7 . 7 5}$ & $\mathbf{8 . 7 5}$ & $\mathbf{9 . 7 5}$ \\
\hline
\end{tabular}

TABLE 2 - Scoring guide for total score

\begin{tabular}{lll}
\hline Total Score Quality & \multicolumn{2}{c}{ Classification } \\
\hline $90-100$ & Outstanding & Specialty \\
$85-89.99$ & Excellent & \\
$80-84.99$ & Very Good & Not Specialty \\
$<80.0$ & Below Specialty Quality & \\
\hline
\end{tabular}

Coffee Science, Lavras, v. 13, n. 3, p. 401 - 409, jul./sep. 2018 


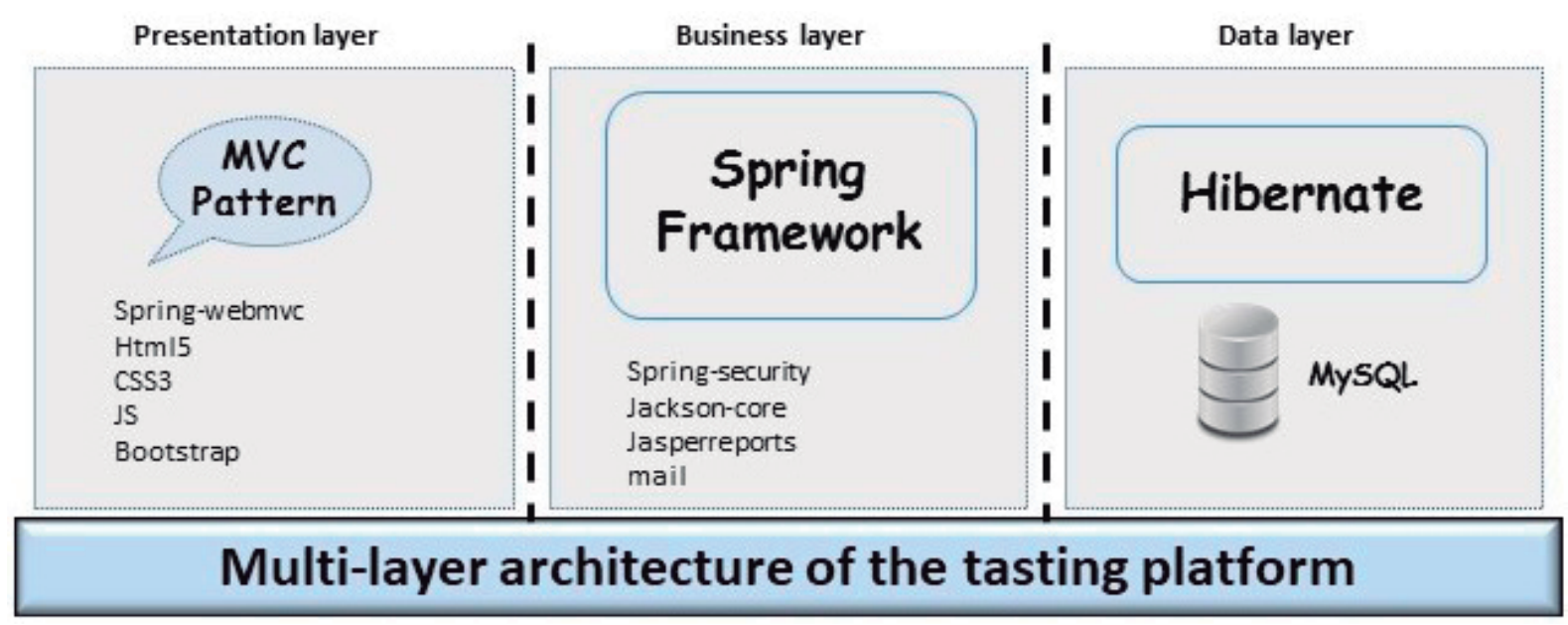

FIGURE 1 - Platform model.

The Figure 2 shows the design of the database application. Since, this is one of the most important parts of the platform, each table is explained below.

user: this table stores the information about each user. Includes the id number, username, password, email, etc.

role: this table stores the types of roles of each user. For this project three types of roles were used: administrator, taster and organizer.

password_reset_token: this table stores the password reset requests.

persistent login: this table allows to remembering the previous sessions established by users.

panel: this table stores information about sensory panels integrated by the tasters.

sample: this table stores information about coffee samples. It includes information such as meters above sea level of the coffee farm, location, coffee farmer name, results of physical analysis, humidity of the sample, etc.

test: this table stores information about results of sensory analysis test performed by the sensory panel.

attribute: this table stores information about the 110 attributes described by the WCR in the new sensory lexicon documentation.

\section{Controllers and services}

The platform is developed in java language using the Spring Framework for the control of the server and Hibernate for the persistence of information in the database. The following describes the technologies used for the control and services into the business layer:
Jasperreports $\mathrm{V}$ 6.3.0: for automatic generation of reports in PDF and EXCEL.

Springframework $V$ 4.3.6: $\quad$ spring framework for server control.

Springsecurity V 4.0.4: security framework for application control

Hibernate V 4.3.11: persistence control with the database

Mysql-conector-java: MySQL database connection library with java.

Jackson V 2.8.7: high performance JSON processor for java.

The objects used are mapped from the database using Hibernate. These entities are controlled from the server and with them the editing, deletion, consultation or insertion of the data is performed. The objects receive exactly the same name from the tables in the database that we mentioned earlier.

\section{Design of the views}

For the design of the platform, the MVC design model (model - view - controller) was used. The model contains all information or information system status, the controller is responsible for presenting the model to the user through the view or graphical interface. The visual design was implemented in a web interface using the following languages and frameworks:

\section{Used languages}

HTML5: used for the labeling of the structure of the views in HTML format.

CCS3: style sheets that controls the appearance of the pages.

JS: interpreted programming language, which controls the functions on the client side. 


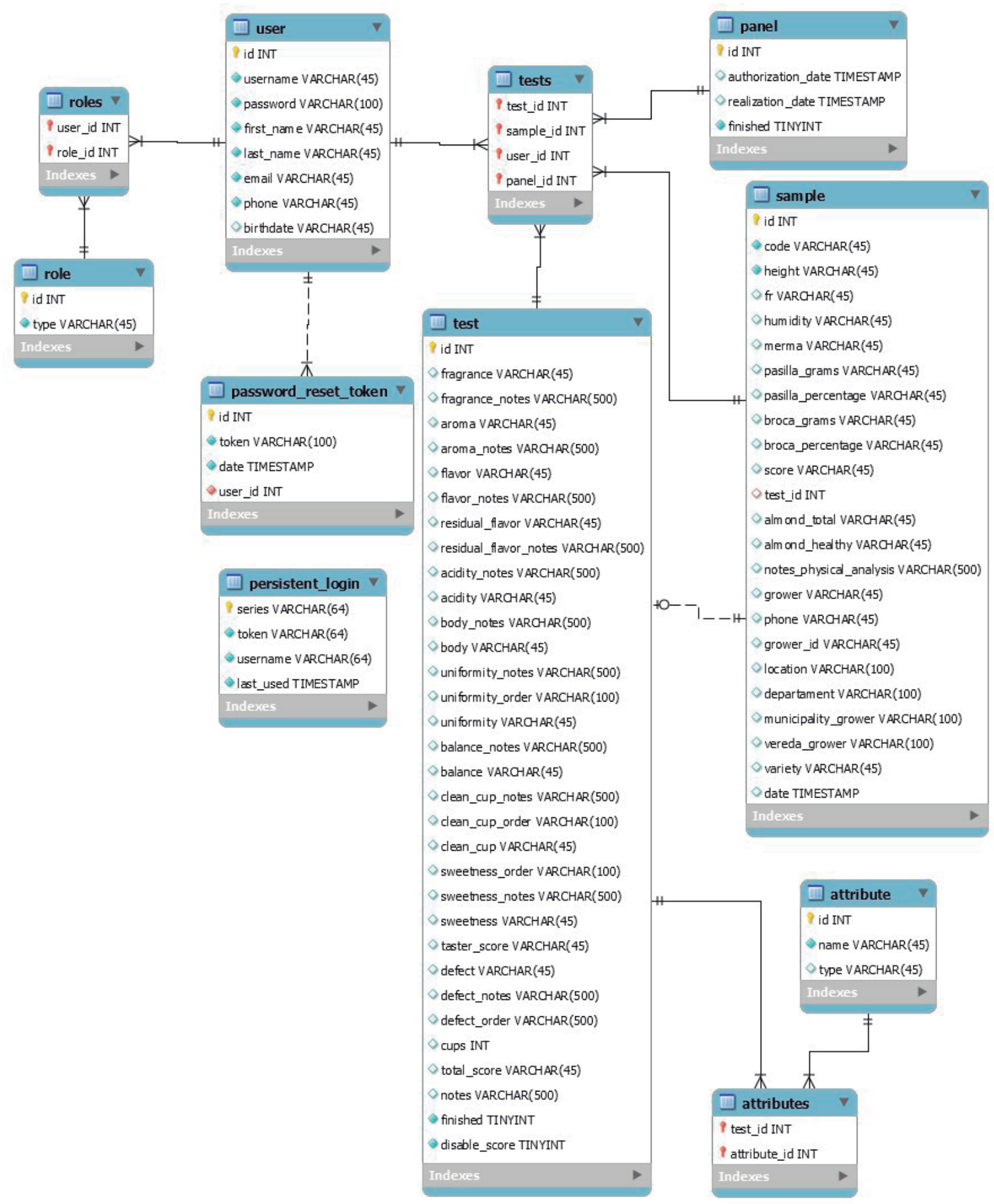

FIGURE 2 -Platform database.

\section{Used languages}

Bootstrap v4.0.0-alpha.6: is a set of web design tools with HTML, CSS and JS.

Font Awesome v 4.7.0: It is a typographic font which contains a set of icons for the interpretation and description of functions.

Jquery v 3.2.1: is a Javascript library which simplifies the interaction of the pages with the web client. 


\section{RESULTS AND DISCUSSION}

The project that resulted in the design and implementation of this information system for special coffee tasting was executed by the Signal and Telecommunications Treatment Group GTST of the Surcolombiana University. It is an application designed for the analysis and treatment of coffee samples. It is aimed at the structuring of the test model for the sensory analysis of samples in a digital environment, which allows to achieving greater speed in obtaining results and a more organized management of information.

The platform can be accessed with the authorization of the administrator through the following URL: http:/gtst.usco.edu.co:8080/ cesurcafe/. Part of the source code can be downloaded through_https://github.com/albecor/ CataCoffeSCAA.

\section{Platform description}

Figure 3 shows the start page of the platform. In this, general information about the research center can be seen. The platform has English/Spanish language support, which can be switched from the EN icon in the top bar.

Users have three different roles according to the privileges assigned to them in the platform. These user roles are:

Administrator: users with this role can add, edit or delete users of the platform.

Organizer: users with this role can add tasting role users to the platform. They must also take care of the identification of the samples and the organization of the tasting panels.
Taster: users with this role can perform the sensory analysis tests of the samples.

All users have permission to edit their profile to update their contact information. Figure 4 shows the profile of the Organizer immediately after entering the system. As the figure shows, the functions of the Organizer are divided into three groups.

Users: Through this group of functions the organizer can add, update or delete users.

Tasting even: Through this group of functions, the organizer can create and organize tasting sessions or events, add panels of tasters to tasting sessions, authorize tasting sessions, view the status of any tasting session and generate reports.

Samples: Through this group of functions, the organizer can add, edit or eliminate coffee samples on the platform. The information about the samples can also be consulted.

The panels of tasters are groups of trained people who carry out the cupping or sensory tests of one or several samples of specialty coffee. To add samples, it is necessary to register on the platform information about weight, meters above sea level, variety, humidity, drill bit, performance factor, name of coffee farmer, telephone, location, etc., which requires an analysis and preparation of the samples.

Figure 5 shows the view through which each taster enters the score for each sample; as can be seen in the figure, the test is in accordance with the protocols defined by the SCAA and the new lexicon of the WCR as mentioned above.

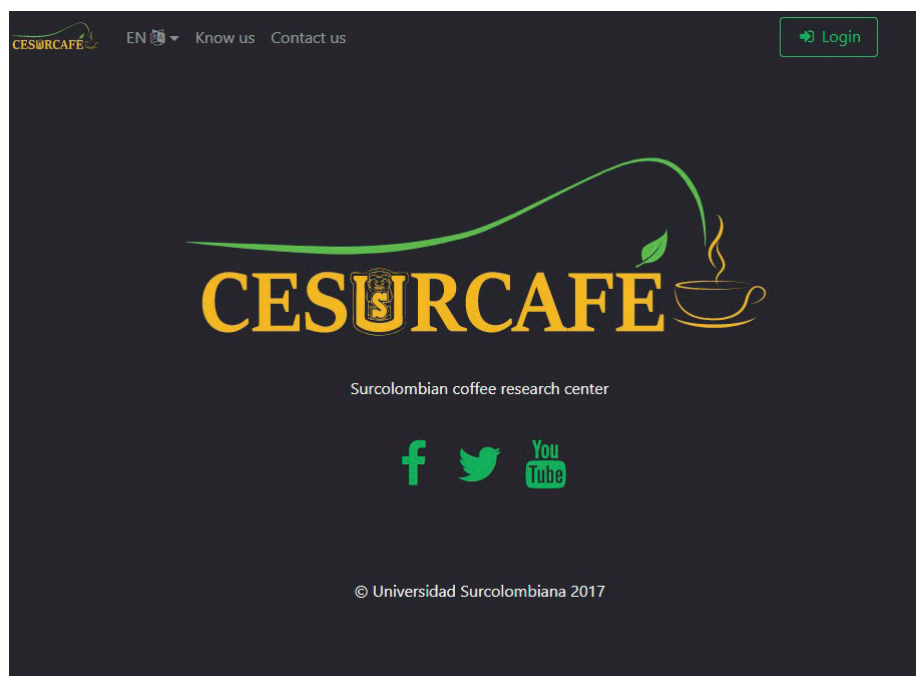

FIGURE 3 - Startig page. 


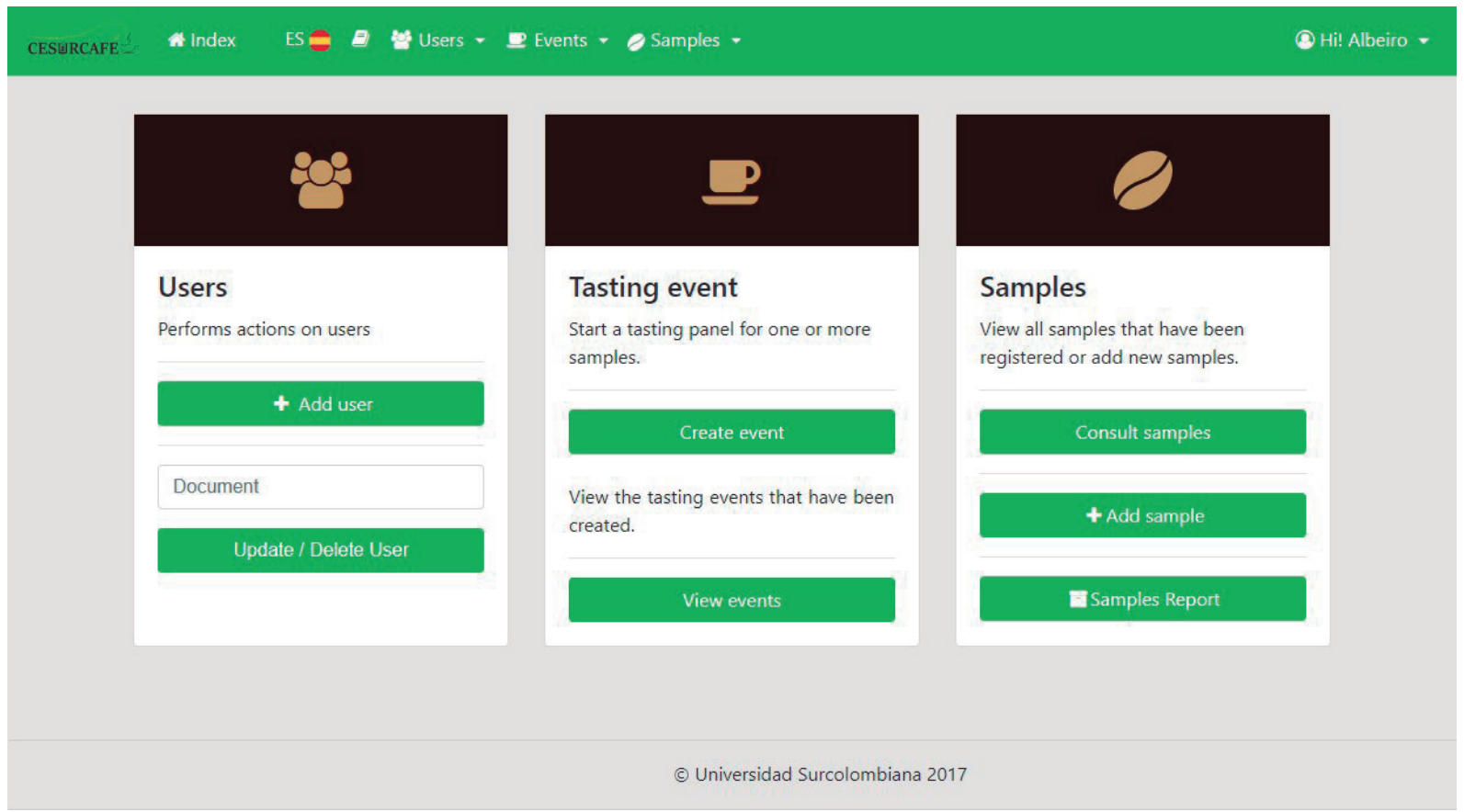

FIGURE 4 - Organizer user profile.

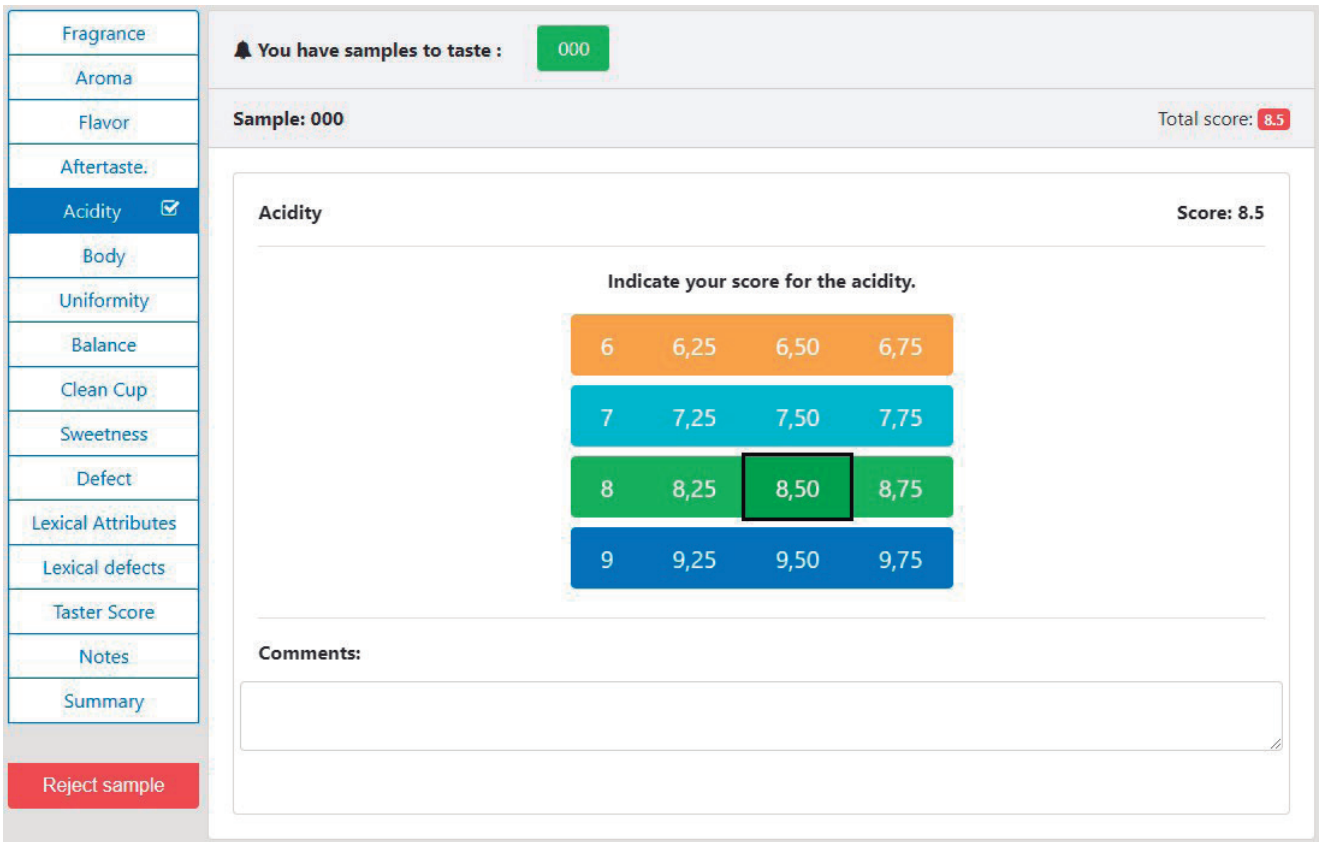

FIGURE 5 - View for samples scoring.

The results of the sensory analysis can be seen with the information from the coffee sample. When several tasters are involved in the sensory test of the sample, then the final result is averaged. The results of each taster's tests can also be seen in the sample information. These results can also be seen on a radar chart from the application as shown in Figure 6.

Once the tasting session is finished, the platform allows you to create multiple reports in HTML, Excel and PDF formats. It is possible to generate reports by sample, by taster, by session, etc. 


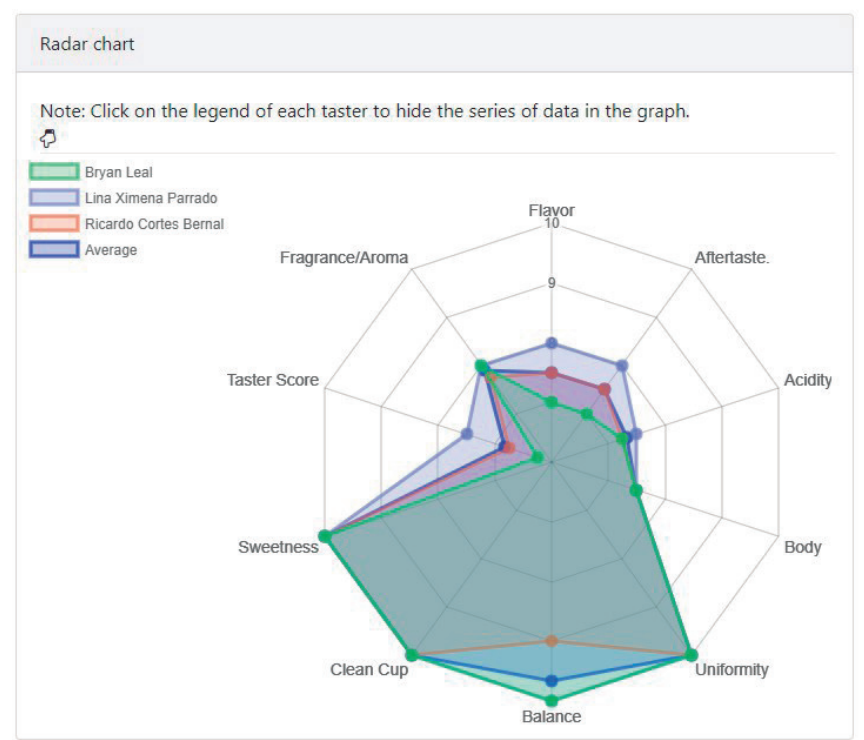

FIGURE 6 - Radar chart.

\section{CONCLUSIONS}

Through this article, the design of a web platform was presented to facilitate the storage and processing of information about the results of cupping tests of specialty coffees. The platform was designed by the Signal Processing and Telecommunications Group for the laboratory of the Southcolombian Center for Research in Coffee - CESURCAFÉ of the Surcolombiana University in Colombia, but it can be easily extended to any laboratory in the world.

The work is designed to structure the test model created by the SCAA for the sensory analysis of the samples, but in a digital environment, in such a way that allows greater agility in the treatment of results and a more organized management of information. In addition, the platform takes into account and includes the new sensory lexicon created by World Coffee Research.

This tool was also designed with the aim of being used in current and future research that is being developed in CESURCAFÉ, so it is expected to have a great impact in the Huila region and in coffee growing countries. Finally, it is important to note that as far as is known, this is the first tool developed for this purpose, which makes this project an innovative one.

\section{ACKNOWLEDGMENTS}

This work was funded by the Investigation Center CESURCAFÉ and the investigation group GTST from Surcolombiana University in Colombia.

\section{REFERENCES}

ALVES, R. C.; CASAL, S; OLIVEIRA, M. B. Tocopherols in coffee brews: Influence of coffee species, roast degree and brewing procedure. Journal of Food Composition and Analysis, Maryland, v. 23, n. 8, p. 802-808, Dec. 2010.

BICHO, N. C. et al. Quality assessment of Arabica and Robusta green and roasted coffees - A review. Emirates Journal of Food and Agriculture, Abu Dhabi, v. 25, n. 12, p. 945-950, Nov. 2013.

CHAMBERS, E. et al. Development of a "living" lexicon for descriptive sensory analysis of brewed coffee. Journal of Sensory Studies, St. Paul, v. 31, n. 6, p. 465-480, Nov/Dec. 2016.

DI BELLA, G. et al. Plasticizer residues by HRGC-MS in espresso coffees from capsules, pods and moka pots. Food Control, Reading, v. 41, p. 185-192, July. 2014.

DI DONFRANCESCO, B.; GUTIERREZ, N.; CHAMBERS IV, E. Comparison of results from cupping and descriptive Sensory analysis of Colombian brewed coffee. Journal of Sensory Studies, St. Paul, v. 29, n. 4, p. 301-311, Sept/Oct. 2014.

FERIA, A. M. Examining the case of green coffee to illustrate the limitations of grading systems/expert tasters in sensory evaluation for quality control. Food Quality and Preference, Harlow, v. 13, n. 6, p. 355367, Sept. 2002. 
MYSQL. MySql community edition. Version 5.7. Available on: $<$ https://www.mysql.com/>. Access in: 3 Mar. 2018.

OYOLA, S.; TRUJILlO, D.; GUTIÉRREZ, N. Aplicación del proceso analítico jerarquico AHP para definir la mejor taza en evaluación de cafés especiales. Coffee Science, Lavras, v. 12, n. 3, p. 374-380, July. 2017.

PICCINO, S. et al. Aromatic composition and potent odorants of the "specialty coffee" brew "Bourbon Pointu" correlated to its three trade classifications. Food Research International, Campinas, v. 61, p. 264-271, July. 2014.
SEPÚLVEDA, W.S.; CHEKMAM, L.; MAZA, M.T.; MANCILLA, N.O. Consumers' preference for the origin and quality attributes associated with production of specialty coffees: Results from a cross-cultural study. Food Research International, Campinas, v. 89, p. 997-1003, Nov. 2016.

SPECIALTY COFFEE ASSOCIATION OF AMERICA. SCAA. Protocols: coffee cupping standards. Version Feb. 2018. Available on: <http:// scaa.org/?page=resources\&d=cupping-standards $>$. Access in: 2 Mar. 2018.

SPRING FRAMEWORK. Spring Framework. Available on: <https://spring.io/>. Access in: 3 Mar. 2018. 